\title{
DEVELOPMENT OF LM10-MIRA LIQUID OXYGEN - LIQUID NATURAL GAS EXPANDER CYCLE DEMONSTRATOR ENGINE
}

\section{P. Bellomi ${ }^{1}$, M. Rudnykh ${ }^{2}$, S. Carapellese ${ }^{1}$, D. Liuzzi $^{1}$, G. Caggiano ${ }^{1}$, L. Arione ${ }^{1}$, A. A. Gurtovoy ${ }^{2}$, S. D. Lobov ${ }^{2}$, V.S. Rachuk ${ }^{2}$, E. D'Aversa ${ }^{3}$, A. De Lillis ${ }^{3}$, and R. C. Pellegrini ${ }^{3}$}

${ }^{1}$ Avio S.p.A

Via Ariana km 5.2, Colleferro (Rome) 00034, Italy

${ }^{2}$ OSC "Konstruktorskoe Buro Khimavtomatiki"

20 Voroshilov Str., Voronezh 394006, Russia

${ }^{3}$ ASI - Launchers and Space Transportation Unit

Via del Politecnico, Rome 00133, Italy

\begin{abstract}
This article contains results of joint works by Konstruktorskoe Buro Khimavtomatiki (KBKhA, Russia) and AVIO Company (Italy) on creation of the LM10-MIRA liquid-propellant rocket demonstrator engine for the third stage of the upgraded "Vega" launcher. Scientific and research activities conducted by KBKhA and AVIO in 2007-2014 in the frame of the LYRA Program, funded by the Italian Space Agency, with ELV as Prime contractor, and under dedicated ASI-Roscosmos interagencies agreement, were aimed at development and testing of a 7.5-ton thrust expander cycle demonstrator engine propelled by oxygen and liquid natural gas (LNG).
\end{abstract}

\section{INTRODUCTION}

In 2004, when the development of the Vega launcher was still ongoing, ASI started the investigation of those potential areas where evolution of the launcher could be envisaged, with the aim to reach improvement of performance, reduction of costs, and use of a liquid 'green' engine.

The feasibility study selected the three-stage configuration of the new launcher, named Lyra and defined the main architecture of the propulsion system using liquid oxygen (LOx) and methane.

(C) The Authors, published by EDP Sciences. This is an open access article distributed under the terms of the Creative Commons Attribution License 4.0 (http://creativecommons.org/licenses/by/4.0/). 
Under the frame contract for 'Lyra phase B' committed by ASI to the Vega system architect ELV, the contractual collaboration on propulsion activities between KBKhA and AVIO started in 2007, under the umbrella of a dedicated interagencies agreement between ASI and Roscosmos, following the intergovernment "Agreement between the Government of the Italian Republic and the Government of the Russian Federation on Cooperation in the Exploration and Use of Outer Space for Peaceful Purposes," signed in Moscow on November 28, 2000 .

The first phase of joint works on the LM10-MIRA engine was aimed for the concept design of the 10-ton-class thrust LM10-MIRA flight engine propelled by LOx and LNG. Successful completion of this phase of activities in 2008 allowed to start the next phase of works that involved design, manufacture, and testing of the 7.5-ton thrust LM10-MIRA demonstrator engine (further referred to as the demonstrator). In June, 2014, LM10-MIRA demonstrator engine firing test campaign has been successfully accomplished at Voronezh (Russia) premises.

In order to conduct the contractual activities, a joint team of AVIO and KBKhA leading specialists was formed. The team successfully completed the scope of design, manufacturing, and testing works in full compliance with both European and Russian standards.

\section{DESIGN AND MANUFACTURE OF THE DEMONSTRATOR ENGINE}

The demonstrator was designed and manufactured on the basis of jointly developed and mutually approved technical specifications that reflected requirements to the components design and characteristics.

In process of the demonstrator's development, designers took into account the scientific and technical base on the oxygen-hydrogen RD0146U expander cycle engine created by KBKhA by request of Roskosmos. By now, the RD0146U engine has been tested for 77 times and its total operation is over $4000 \mathrm{~s}$. The use of expander cycle has confirmed high reliability, simplicity of design, low development cost, and good performance of the engine.

It is necessary to mention that LM10-MIRA contractual activities involved usage of a background unique bases created independently by KBKhA's and AVIO in the field of liquid propellant engines, within the frame of the Russian Space Program and of the Italian National Research Program.

\section{Development of the RD0110M Open Cycle Generator Engine}

To demonstrate the possibility of transferring the RD0110 oxygen-kerosene fourchamber liquid-propellant rocket engine to the oxygen-methane version, KBKhA 


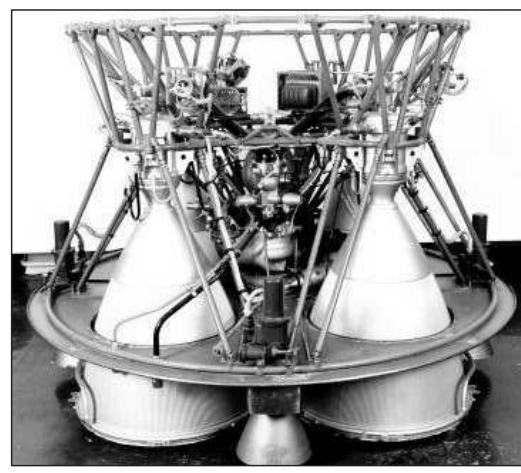

(a)

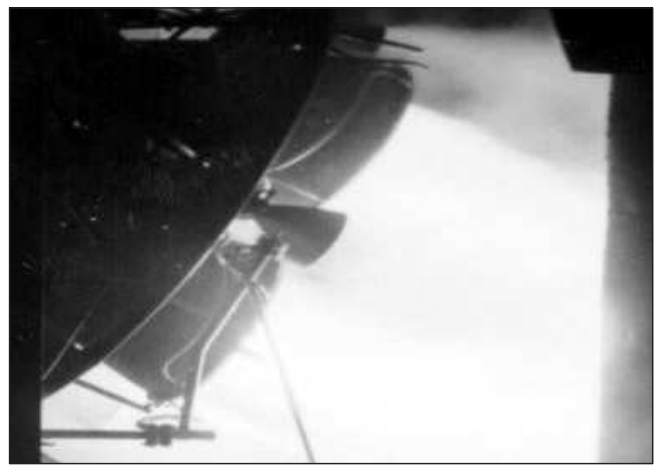

(b)

Figure 1 The RD0110M engine (a) and its fire test at KBKhA's test facility $(b)$

conducted design, experimental, and technological activities. As a result, in 1998, an engine fuelled by LNG was fire tested. Liquid natural gas with more than $92 \%$ of methane content has been used. The engine was named RD0110M. In the course of testing, a scope of assigned tasks was successfully solved and the possibility of the engine's transfer to methane with minimal design changes was confirmed.

The RD0110M engine and the picture of its fire test at KBKhA's test facility is given in Fig. 1.

To be noticed that up to now, the original oxygen-kerosene RD0110 engine has been successfully used in the "Soyuz" carrier rocket.

\section{Development of the RD0146M Expander Cycle Engine}

The RD0146M engine created by KBKhA on the basis of the oxygen-hydrogen engine components is fully founded on design and technological solutions for the RD0146 engine. In 2007, at KBKhA test facility, a cycle of the RD0146M fire tests was successfully conducted with 6 ignitions and total operation time of $200 \mathrm{~s}$.

In process of the RD0146M engine test preparation and testing, KBKhA gained unique experience of work with LNG, successfully solved a set of tasks on implementation of stand technologies for working with LNG as well as the tasks on experimental development of multiple engine startups during one startup day.

The RD0146M engine and engine fire testing is shown in Fig. 2. 


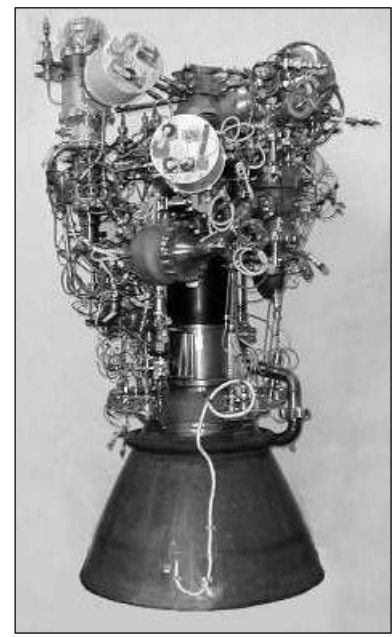

(a)

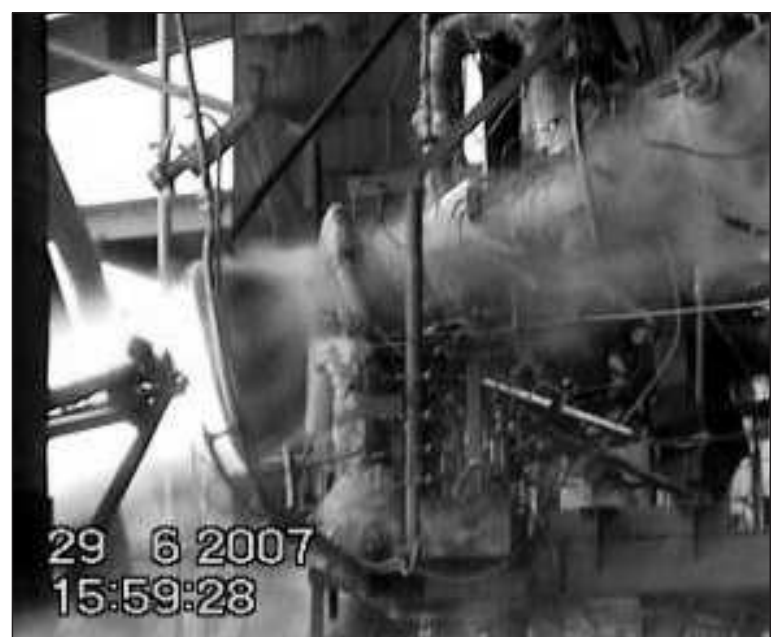

(b)

Figure 2 The RD0146M oxygen-methane engine $(a)$ and its fire test at KBKhA's test facility $(b)$

\section{Scientific and Technical Works on Creation of Oxygen-Methane Engines for Prospective Carrier Rockets within the Frame of the Russian Space Program}

Since 1998, KBKhA conducts scientific, research, experimental, and design activities aimed at creation of the $\mathrm{LOx}-\mathrm{LNG}$ liquid-propellant rocket engines with a wide range of thrusts to be used in prospective carriers.

Thus, by the beginning of 2007, KBKhA had a significant scientific and technical base in development of LNG-fuelled liquid-propellant rocket engines, and this fact significantly influenced the positive decision to sign the contract between KBKhA and AVIO.

Also, AVIO side background obtained in the frame of Italian national under ASI patronage and international under ESA contracts activities has been profited for LYRA program.

\section{Liquid Oxygen - Gaseous Methane Combustor Heritage}

At the beginning of 2000, AVIO have completed realization of the firing test facility, so-called FAST2 facility, and starts an experimental activities on LOx $/ \mathrm{GCH}_{4}$ (gaseous methane) combustion testing. The Subscale Thrust Chamber Assy (constituted by chamber, injector head, and ignition elements) designed and 


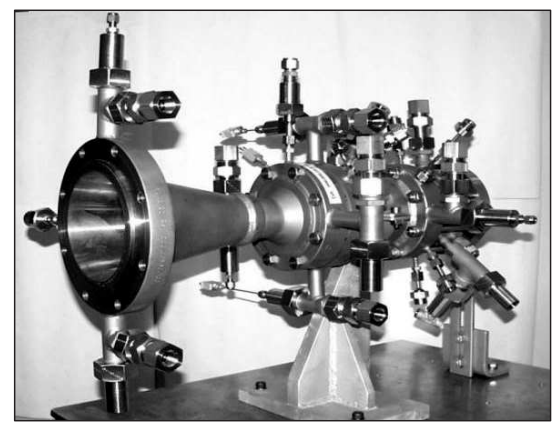

(a)

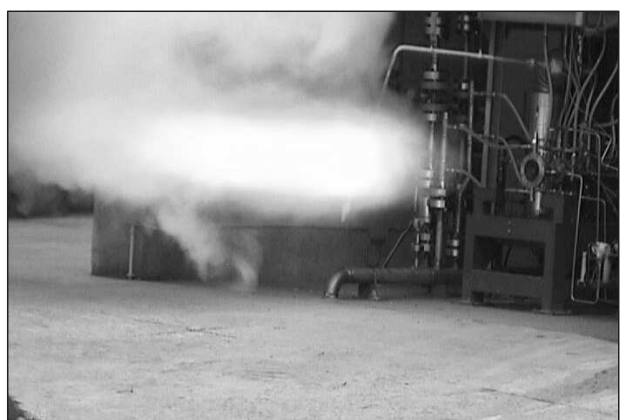

(b)

Figure 3 The $\mathrm{LOx} / \mathrm{GCH}_{4}$ combustor $(a)$ and commissioning firing test at FAST2 facility $(b)$

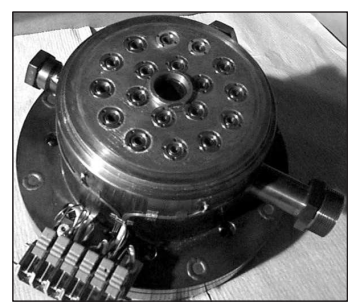

(a)

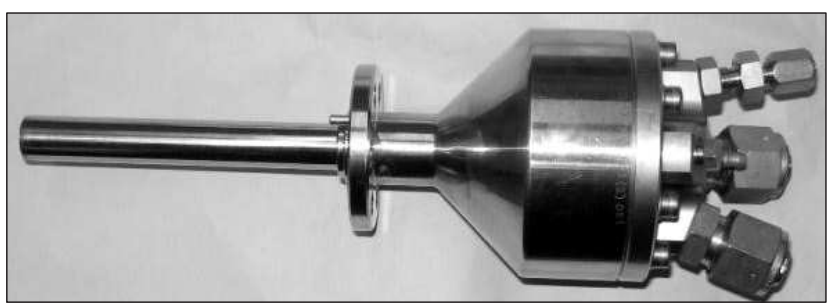

(b)

Figure 4 The AVIO first injector head $(a)$ and igniter $(b)$

manufactured by external supply has been used for FAST2 facility commissioning (Fig. 3). This step was the preliminary one to achieve "know how" in test stand tuning and managing.

Following the first success, AVIO investigated the design and manufacturing of its Injector Head and Ignition System. In 2006-2007, the first Injector Head made by AVIO has been successfully tested with Igniter designed and manufacture by AVIO (Fig. 4). These activities were the base for the development of MIRA Subscale Injector Head and for the MIRA Demonstrator Injector head design.

\section{Turbopump Heritage for FTPA Design}

Since late 1980s, AVIO is designing and manufacturing Oxygen turbopump (TP) for the Ariane Oxygen/Hydrogen rocket engines. In particular, Oxygen TP for 


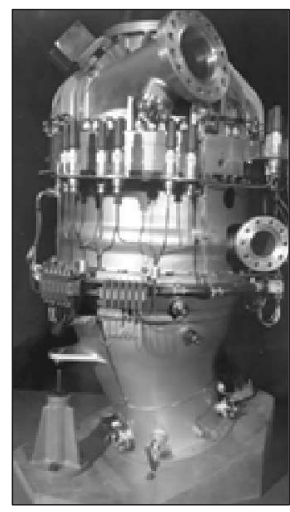

(a)

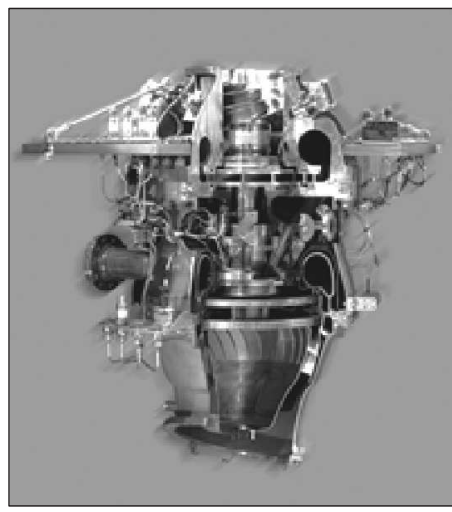

(b)

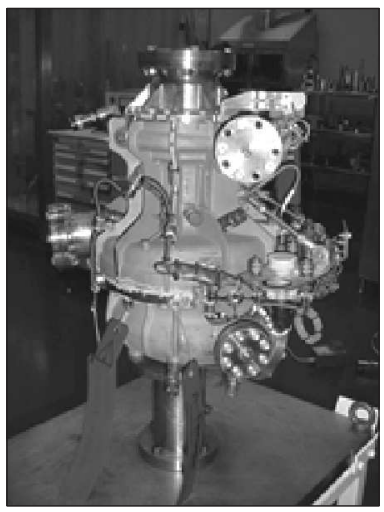

(c)

Figure 5 Vulcan $1(a)$, Vulcan $2(b)$; and VINCI $(c)$ oxygen TPs

Vulcain 1 engine, Vulcain 2, and Vinci were successfully designed, manufactured, and tested (Fig. 5). This is a result of years of research, tribological activity, technological programs, components testing, and know-how.

AVIO has also designed and manufactured rigs for subcomponents testing such a pump in water, bearing in $\mathrm{LOx}$ and seals in $\mathrm{LOx} / \mathrm{He} / \mathrm{GN}_{2}$ (gaseous nitrogen). Such subcomponents activity was performed directly on AVIO bench premises in Colleferro (for pump-water testing) and Torino (for bearing/sealsLOx testing).

MIRA FTPA turbine design has been the result of turbine background in the aeronautic jet-engine.

Based on this owned experiences, KBKhA and AVIO approached the design of the LM10-MIRA engine with a full share of the overall "engine system" responsibility.

\section{LM10-MIRA Demonstrator Engine}

A simplified scheme of the demonstrator engine is shown in Fig. 6.

Compared to the flight engine, the Demonstrator represents the identical thermodynamic cycle, architecture, and thrust level but it has been optimized with the final goal to minimize time and cost impact. Following this objective, the most part of prototype engine (RD-0146U KBKhA) has been used. At the same time, the critical components (Injector Head and Fuel TP) needed for LNG application have been newly developed by AVIO. 


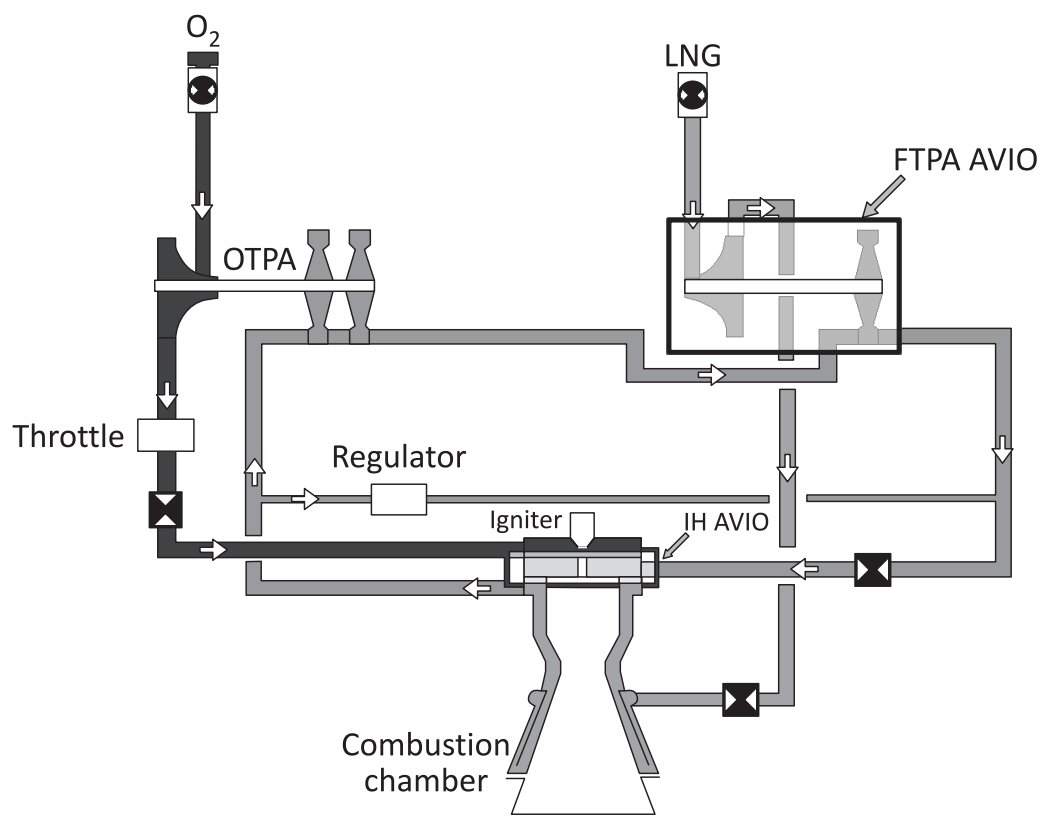

Figure 6 LM10-MIRA Demonstrator engine simplified scheme

\section{The Chamber Development}

In the process of development, the chamber's thermodynamic, gasdynamic, and strength calculations were conducted. The demonstrator's chamber consists of the injector head created by AVIO and the chamber unit created by KBKhA. The design of Injector Head had involved several tasks that are schematically presented in Fig. 7.

The first step of Injector Head design was the selecting of single injector element type. Many tests were performed on several types of injectors: principally shear coaxial injectors and the swirled one.

With testing activities performed on single elements, the following skills have been learned:

- link between injector performance and geometrical dimensions: injector recess, injector diameters at outlet section, and injector length; and

- single injector layout with low deviation on performance: a single injector is generally made by at least two parts (posts + sleeves) and its mutual integration affects the overall performance of single injector.

In order to have a robust design, save cost, and mitigate uncertainties on injector performance, the recessed shear coaxial element was selected. 


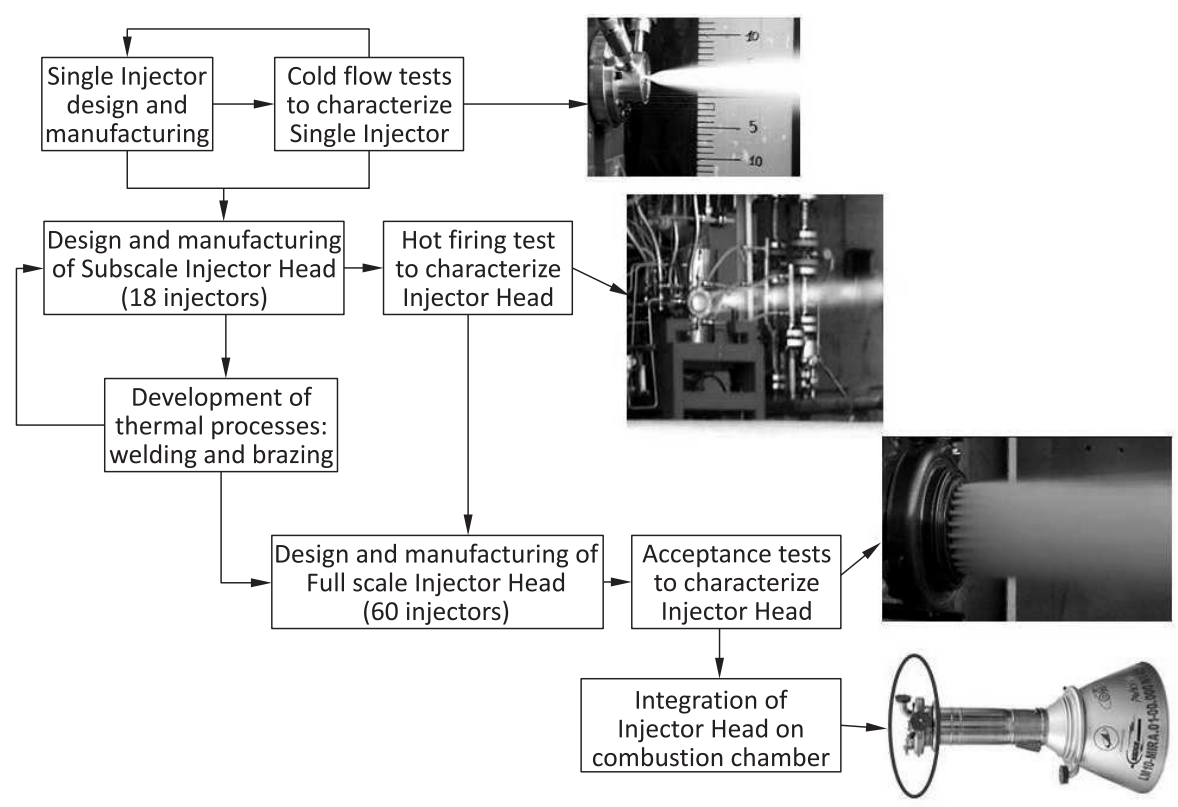

Figure 7 Development logic of Injector Head

Once selected the single injector element, the design of Subscale Injector Head (18 elements) was started and during this task, the following technological issues were solved: dedicated thermal processes were developed to braze Inconel elements and to weld internal parts of Injector Head. Regarding the welding processes, traditional and laser welding processes were developed for Inconel elements; and arrangement of internal parts of Injector Head to minimize the time and cost to manufacture and integrate all parts and to maximize robustness and safety of Injector Head.

To confirm the performance of single injectors tasks, the Subscale Injector Head was tested in Colleferro in 2009-2010 with several hot firing tests. During these tests, it was useful to check the Single Injector performance in a wide range of mixture ratio and chamber pressure: the range of combustion chamber pressure achieved during test was $57-67$ bar (the design value is 60 bar); and the range of propellant mixture ratio achieved during test was 2.8-4.1 (the design value is 3.4 ).

After Subscale testing, the design of Full Scale Injector Head (60 injector elements) was started and skills (acquired during Subscale design) on internal Computational Fluid Dynamic analysis (reacting and frozen analyses) and Finite Element Model analysis was improved. The Injector Head resulting by the design tasks is presented in Fig. 8. 


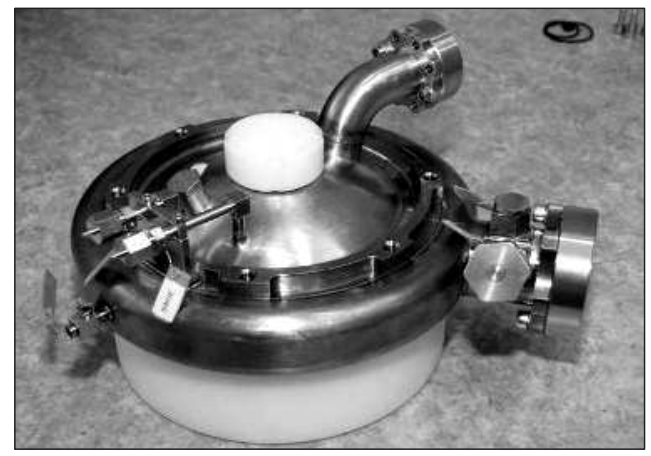

Figure 8 LM10-MIRA Injector Head

To verify Injector Head behavior and characteristics, dedicated tools and procedures were developed to perform cold test activity in Colleferro (before integration of Injector to Combustion chamber).

Once verified the characteristic of Injector Head that completely fulfill the technical specification, the Injector Head and the chamber unit were welded together at the production plant of KBKhA. External view of the finalized and inspected thrust chamber assembly is given in Fig. 9. The chamber nozzle outlet section diameter is $710 \mathrm{~mm}$.

To confirm the technical specification requirements, the trust chamber assembly fire tests were conducted in the frame of the newly developed UE2 experimental unit. The scheme of the unit (Fig. 10) and the fire tests program were developed by the AVIO

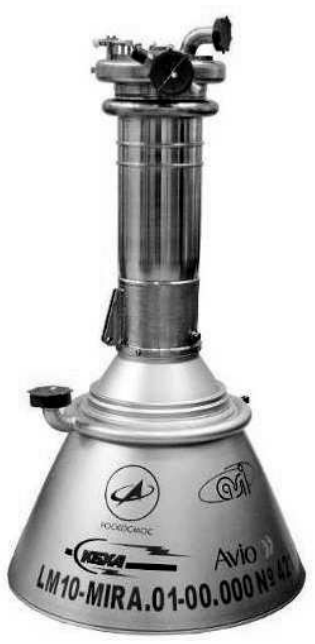

Figure 9 External view of the Thrust Chamber Assembly and KBKhA specialists. The main task of this experimental tests campaign was to confirm the design, performance, and safety of the newly developed injector head before to proceed with the test campaign at the engine level. The combustion chamber cooled by LNG was previously tests by KBKhA on the previously mentioned RD0110M engine; then, in the current test campaign, the chamber was chilled by water to have a simpler and cheaper test campaign.

The program of UE2 tests conducted at KBKhA test facility included 7 firing tests with total duration of $118 \mathrm{~s}$. In the process of testing, the parameters of 


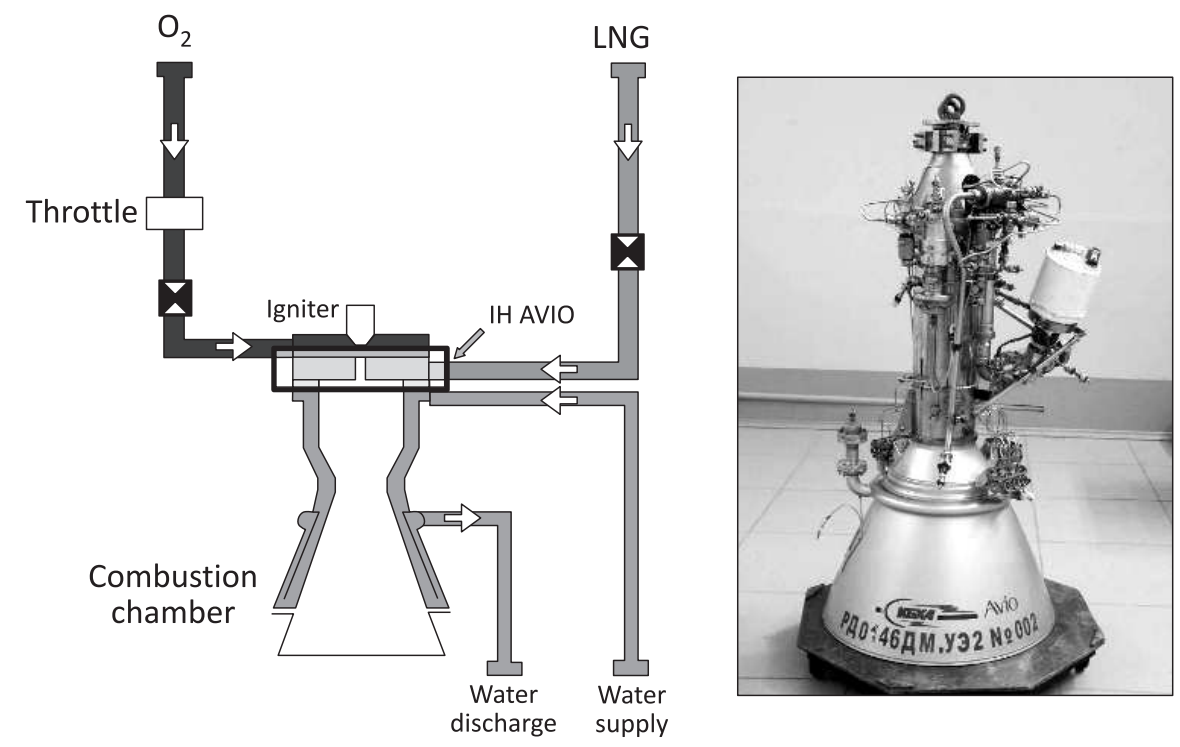

Figure 10 The UE2 experimental unit

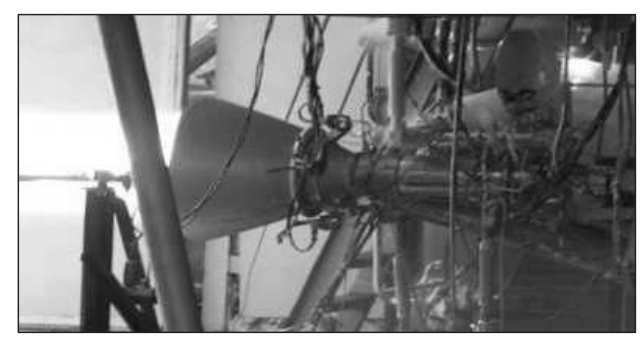

Figure 11 Firing test of the chamber in the frame of the UE2 unit

the chamber reached the assigned values. The mixture ratio value 3.4 has been achieved. Full compliance with the test task requirements was achieved.

Figure 11 shows the UE2 unit during firing test.

During firing tests, the following main tasks were successfully completed:

- operability of the chamber developed by KBKhA and AVIO was confirmed;

- experimental data on operation of the chamber in startup, main, and shutdown conditions were obtained;

- the chamber's operation cyclogram was confirmed; 
- the chamber was tested within the wide range of fuel temperatures at the injector head inlet;

- the chamber's cooling ability was checked; and

- combustion stability parameters of the chamber were evaluated.

The whole scope of works on the chamber's creation and fire testing was controlled by the AVIO and KBKhA team with immediate participation of ASI representatives.

\section{FTPA Development}

The new fuel demonstrator TP has been designed for the typical objectives of a technological demonstrator (i. e., technology readiness improvement, technical feasibility of the overall project in view of its development to be performed in the subsequent phase), not optimized for the use in flight.

A trade-off has been performed to identify the best

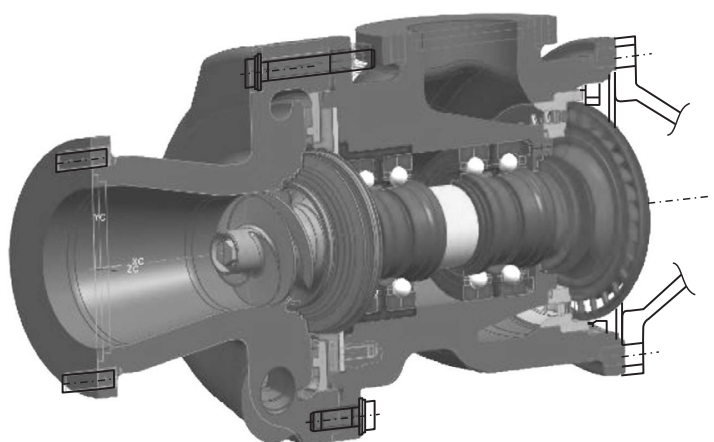

Figure 12 LM10-MIRA $\mathrm{CH}_{4} \mathrm{TP}$ architecture TP architecture (Fig. 12). The configuration chosen is a two-stage pump (axial + radial) with one-stage turbine, and with balls bearings placed between pump and turbine.

Advantages of this solution are to have a subcritical spool, a simpler architecture, and a balancing procedure at low speed. Pump is characterized by a low volumetric mass flow with a high pressure rise made up of only one centrifugal stage. The diffuser and the volute are both designed to minimize the pressure loss due to the very high dynamic pressure.

The turbine is one-stage reaction and particular attention was focused on Manifold and the secondary flow optimization in order to increase the efficiency.

A new technology has been dedicated to manufacture in a short time with lower costs the more complex parts of the TP such as main housings (with pump volute), turbine manifold, and impeller. These parts have been produced by additive manufacturing: Direct Metal Laser Sintering.

To validate the design solutions and to reduce the predicted performances, accuracy testing activities of TP subsystems have been performed on pump (with 


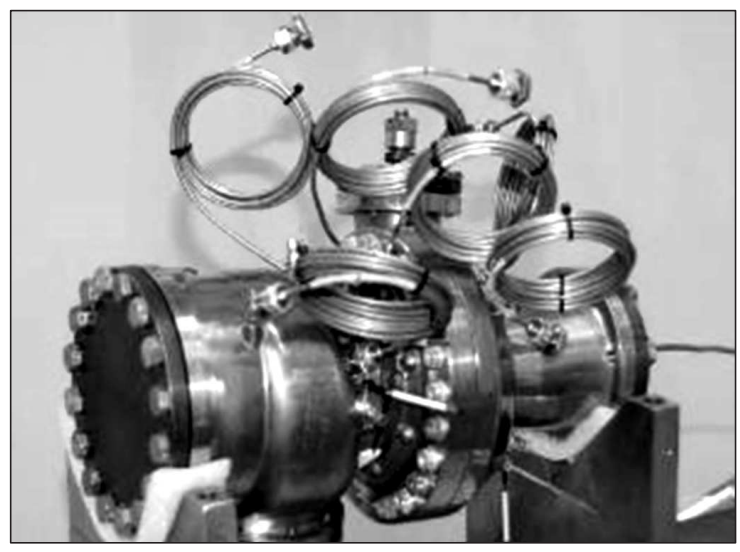

Figure 13 AVIO fuel TP assembly

relevant secondary circuit), turbine, and bearing. In particular, turbine inlet stator test campaign in air; pump testing in water; and bearing testing in liquid nitrogen $\left(\mathrm{LN}_{2}\right)$.

Experimental results, obtained from the FTPA subassemblies testing, were in line with analytical simulations validating that technical solutions, implemented in the design, have been dimensioned correctly (Fig. 13).

\section{Oxidizer Turbopump Assembly Modification}

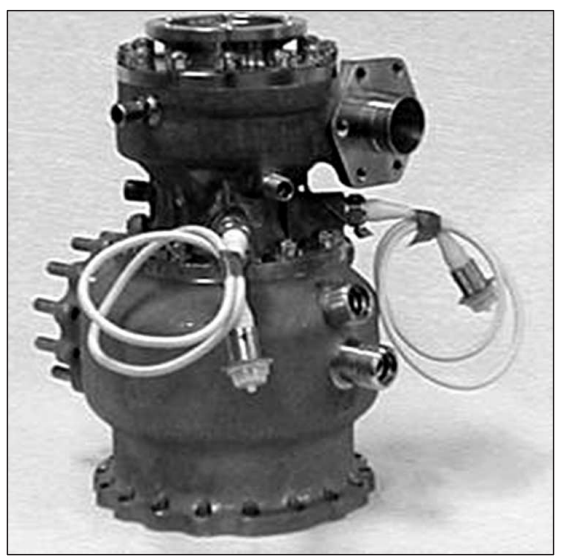

Figure 14 KBKhA OTPA
In the course of works, special attention was paid to design modernization of the oxidizer TP assembly (OTPA) and the igniter device.

During the works with the OTPA (Fig. 14), there was introduced a line for cooling of the OTPA bearings by LNG collected downstream the FTPA pump. This solution provided operability of the bearings in wide ranges and conditions of the demonstrator engine operation.

Based on modernization results, a cycle of the OTPA acceptance tests was conducted in order to control the pump, turbine, and rotor 
characteristics, tightness of the OTPA plug-type connections and values of the flow rate through the floating rings of the interpropellant seal between the pump and the turbine.

The tests proved a full compliance with the design documentation requirements.

\section{Igniter Modification}

Design activities conducted during modernization of the igniter device (Fig. 15) provided reliable ignition of propellants in the chamber, taking into account requirements to the demonstrator's operation in the wide range of external conditions on which, among other things, the minimal propellants flow rate depends.

Successful results of KBKhA components modernization were fully confirmed during the demon-

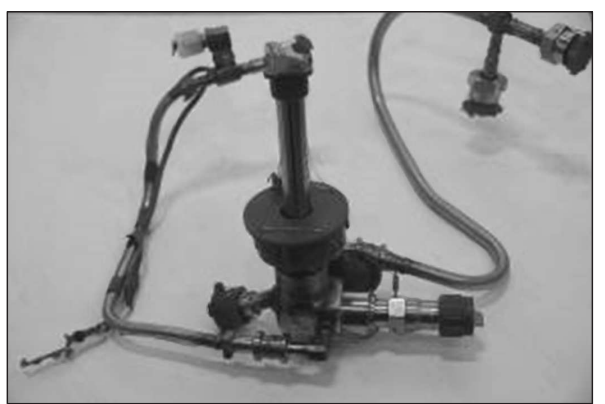

Figure 15 The igniter device strator's fire tests.

\section{The Demonstrator's Assembly}

The demonstrator's assembly was conducted at KBKhA's production plant since January 30 till March 28, 2014 in compliance with the applied documentation. At all stages, the assembly process was controlled by AVIO specialists and all activities were agreed and registered in the engine's accompanying documentation.

The demonstrator's parts and assembly units were manufactured with application of technology and materials developed and used for the engines designed by KBKhA.

Executing the contract, KBKhA implemented a complex of design and technological works on modernization of the RD0146U oxygen-hydrogen engine components to be used in the demonstrator. At KBKhA's stand and experimental facility, the feeding, ignition, control, and regulation systems' components were autonomously tested and the checks confirmed their operability in the frame of the oxygen-methane engine.

The demonstrator's scheme is shown in Fig. 16. A gas discharge line was introduced downstream the OTPA and FTPA turbines to provide operation 


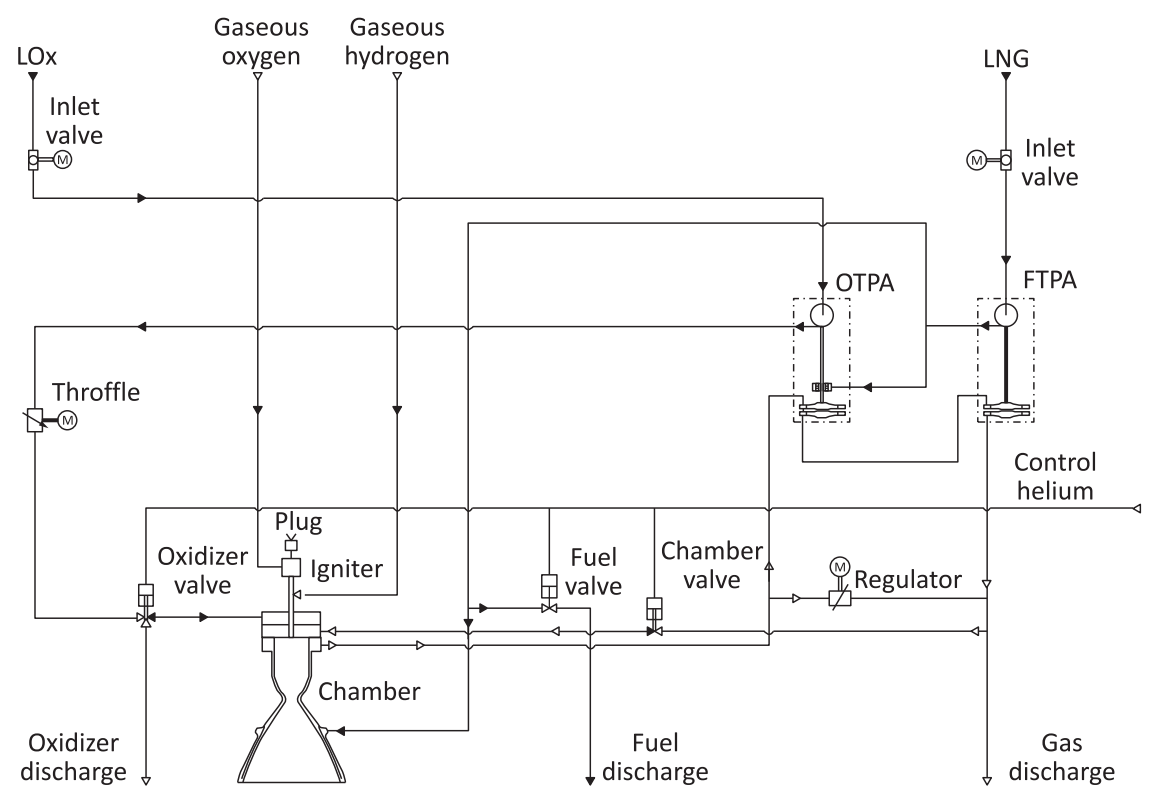

Figure 16 LM10-MIRA Demonstrator simplified scheme

conditions of the oxygen-methane demonstrator. The line gives an opportunity to setup the LNG flow rate through the demonstrator and to conduct chemical analysis of the fuel.

The assembled demonstrator successfully passed all control procedures, including proof and leak tests. Control tests were guided by a workgroup of AVIO and KBKhA specialists in accordance with mutually approved programs and methods that were developed on the basis of the engine's technical specification. External view of the demonstrator is shown in Fig. 17.

Based on the results of joint works on the demonstrator's integration, KBKhA, AVIO, ASI, and ELV board decision has authorized demonstrator shipment to the test facility and mount it on the test stand.

\section{THE LM10-MIRA DEMONSTRATOR TESTING}

The demonstrator test program included three startup days and 11 fire tests with transition to the steady-state mode: the first day -1 fire test with duration of $60 \mathrm{~s}$, the second and the third days -5 fire tests a day with duration of $60 \mathrm{~s}$ each. During the whole test series, total firing time reached the value of over $677 \mathrm{~s}$. 


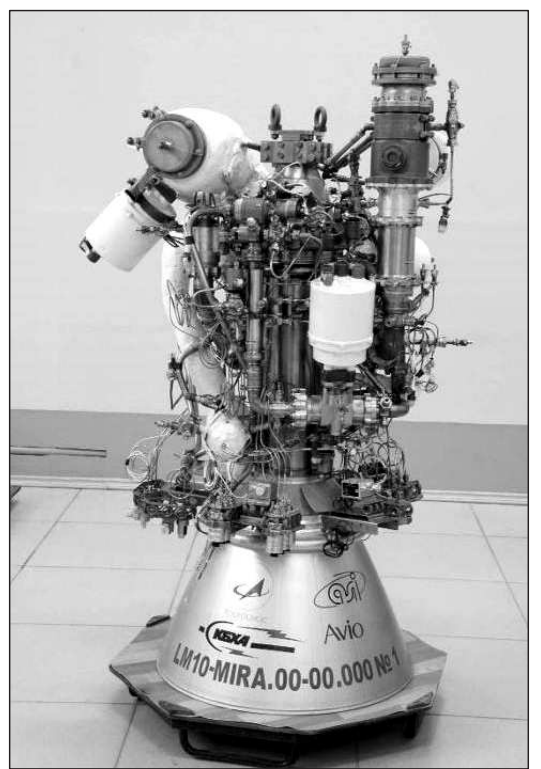

Figure 17 LM10-MIRA Demonstrator assembly

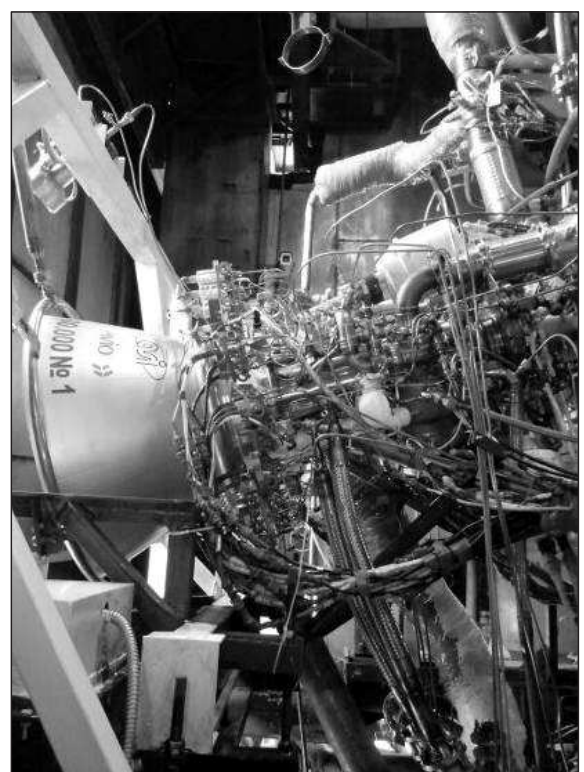

Figure 18 LM10-MIRA Demonstrator on the test stand

The firing tests were aimed at solving the following basic tasks:

- functional check of the demonstrator's assembly;

- evaluation of the demonstrator's steady operation parameters;

- confirmation of possibility for the LOx-LNG expander cycle engine technical implementation;

- study of the demonstrator's LOx-LNG startup with transition to the steady-state main mode;

- study of the demonstrator's operation during the main mode and shutdown;

- check of the demonstrator's startup with vacuum conditions imitation;

- functional check of the chilldown, startup, and shutdown sequence;

- the Safety and Control System algorithms testing; and

- evaluation of the demonstrator's parameters. 
External view of the demonstrator mounted on KBKhA test stand is shown in Fig. 18.

The following logic of the test campaign was established.

In the first and the second test days, the engine settings parameters were adjusted and the engine steady-state mode has been achieved. In addition to this, during the second test day, a startup in vacuum conditions was tested.

The aim of the third test day was to obtain maximum combustion chamber pressure values and nominal mixture ratio. The tests startups were conducted both in atmospheric and in vacuum conditions.

It is necessary to mention that a unique system of regular vacuum conditions imitation for engine startup was specially developed for the demonstrator's firing tests on KBKhA test bench.

On the basis of requirements agreed between KBKhA and AVIO, the following main stand systems were used for testing: propellants supply system; safety and control system; parameter measurement and processing system; gas supply system; propellants utilization system; firefighting, and other systems.

In the course of fire tests preparation, "cold" flow tests were successfully conducted. The tests pursued the following goals: the LOx feeding system operation check, the system's hydrodynamic characteristics definition, setting the system for the assigned modes; and the LNG feeding system operation check, verification of the LNG mass flow calculation method, setting the system for the assigned modes, and other tasks.

Upon completion of the test preparation activities, an official Test Readiness Review was held.

During the Test Readiness Review, KBKhA, AVIO, ELV, and ASI specialists studied the results of "cold" tests, condition of the hardware, related documentation, and the test task. The results of the meeting confirmed that the works were complied with technical requirements. The participants of the meeting came to a conclusion that the stand systems and the demonstrator were ready for fire testing.

As it was mentioned before, the series of tests were conducted at KBKhA test stand in three startup days - on May 16, June 4, and June 24, 2014. The results of all fire tests (Fig. 19) showed that all requirements of the test task were fulfilled; the steady-state mode on the pressure inside the camber and the mixture ratio were provided; and the engine startup with imitation of vacuum conditions was checked.

Figures 20 and 21 reflect how the demonstrator's main parameters with typical behavior changed during the Test No. 4. The oxidizer pressure at the Injector Head inlet, fuel pressure at the Injector Head inlet, and pressure inside the combustion chamber are shown in Fig. 20. Considering the engine inlet interfaces, oxidizer and fuel temperature profiles and mass flow rates are shown in Fig. 21.

After each startup day, authorized specialists of KBKhA and AVIO conducted the demonstrator health monitoring including its components in accor- 


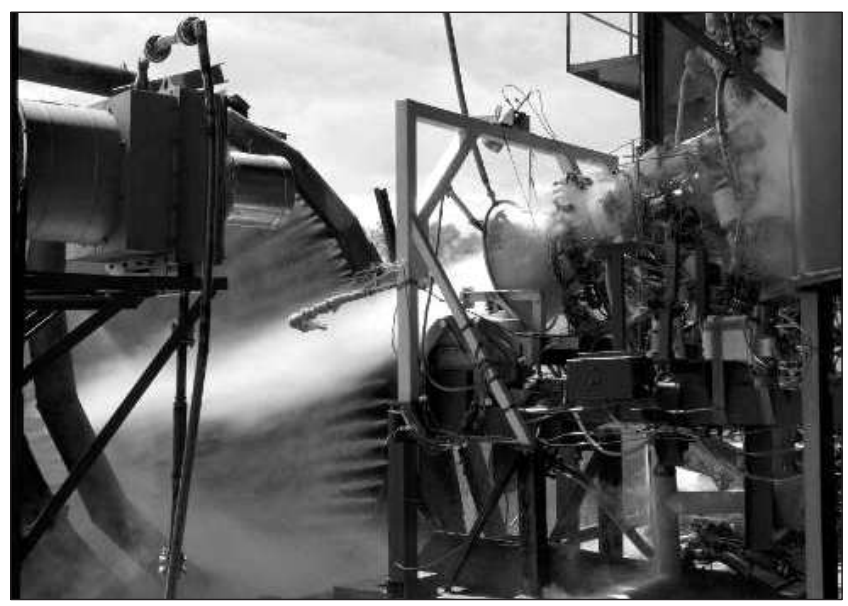

Figure 19 LM10-MIRA Demonstrator engine fire test

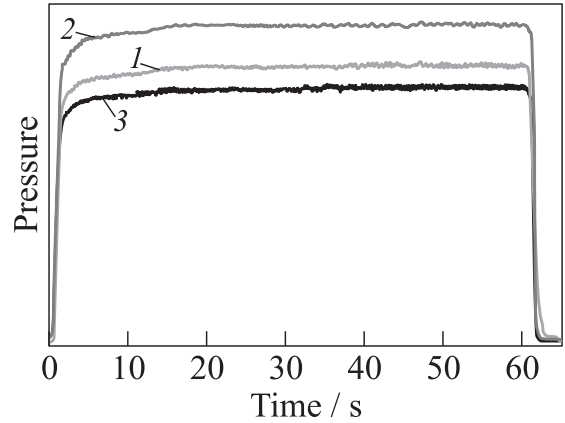

Figure 20 The oxidizer pressure at the Injector Head inlet (1), fuel pressure at the Injector Head inlet (2), and pressure inside the combustion chamber (3)

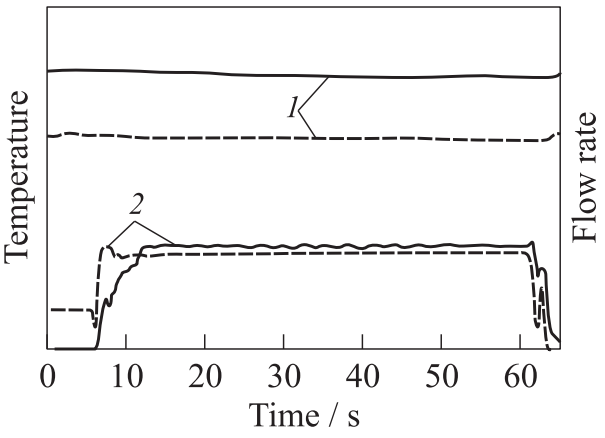

Figure 21 Oxidizer (dashed curves) and fuel (solid curves) temperature profiles (1) and mass flow rates (2)

dance with requirements of the jointly developed specification. The health monitoring results were reflected in the minutes of technical meetings dedicated to the firing tests results and were a necessary condition for go-on decision on further testing.

After the third firing test day, based on the results of all test campaign, Test Review Board has concluded the successful completion of the test activities. 


\section{THE DEMONSTRATOR AS A BASIS OF FUTURE FLIGHT ENGINE}

Activities on the Demonstrator give the chance to verify the capability of the expander cycle to deliver the expected performance and to identify the main critical areas for the final development of the flight engine to be used for VEGA evolution Upper Stage application (chilldown phases, ignition transients, restarts, combustion stability, thermal loads, and cooling effectiveness).

The joint AVIO and KBKhA design team analyzed the impact at system level of the developed subsystem at demonstrator level considering also constraints for the new upper stage.

Due to the stage geometrical constraints and the required performance, the new engine LM10-MIRA has been conceived with a deployable nozzle extension as preliminary choice (to be confirmed). Many solutions have been traded considering different TP architecture (single shaft versus dual shaft), different logic of regulation (but always with the same assumption to have two valves to control the thrust level and the mixture ratio), and different level of chamber pressure.

The required target performance and engine characteristics are resumed in Table 1.

Into an expander cycle, the combustion chamber, apart from ensuring the specified thrust and $I_{\mathrm{sp}}$, should provide for the required fuel temperature at the cooling line outlet that determine the power given to turbines and, consequently, the pressure level that can be reached in the chamber.

Different cooling schemes have been considered in order to guarantee the required outlet temperature (not less than $550 \mathrm{~K}$ ) and the minimum pressure drop.

Table 1 Required target performance and engine characteristics

\begin{tabular}{lc}
\hline \multicolumn{1}{c}{ Parameter } & Meaning \\
\hline Propellants & LOx-LNG \\
Schematic & Expander cycle \\
Thrust in vacuum, $\mathrm{kN}$ & 98.1 \\
Minimum $I_{\mathrm{sp}}$ in vacuum, $\mathrm{kgf} \cdot \mathrm{s} / \mathrm{kg}$ & 364 \\
Total flow rate $(\mathrm{kg} / \mathrm{s})$ & 27.6 \\
Mixture ratio & 3.4 \\
Number of chambers & 1 \\
Thrust vector & $\pm 6^{\circ}$ \\
Max diameter, mm & 1300 \\
Max length, mm & 1900 \\
Weight, kg & $<295.5$ \\
Number of restarts & 5 \\
\hline
\end{tabular}




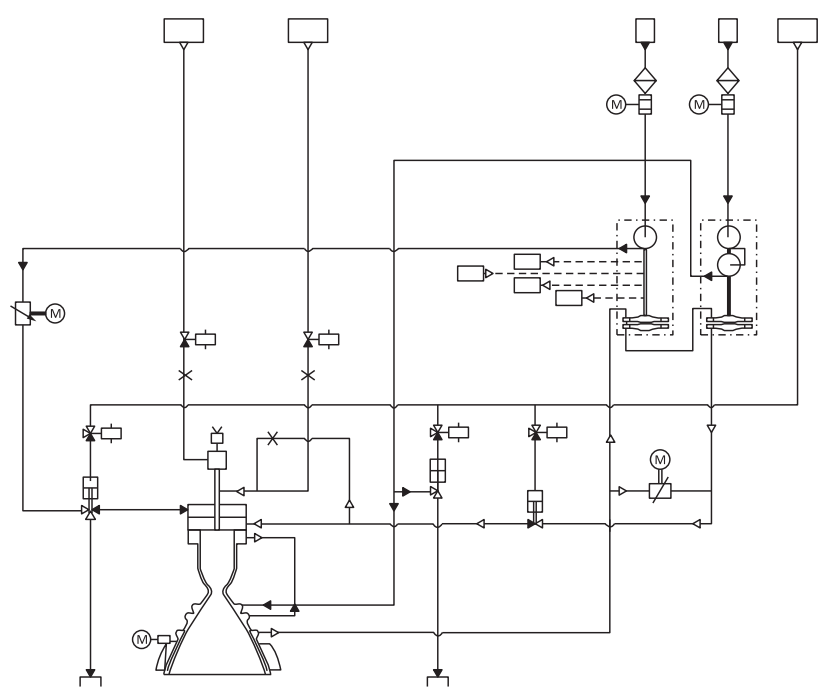

Figure 22 LM10-MIRA flight engine functional scheme

In order to guarantee the required life in term of cycles and cumulated firing time, the maximum wall temperature has been limited to $800 \mathrm{~K}$ for the copper alloy region. The geometry of cooling channels that guarantee this minimum pressure drop coping with given requirements is the first one and this scheme has been selected for the architecture trade-off.

After the trade-off between different architectures for the System Requirements Review preparation, the scheme presented in Fig. 22 has been selected; the peculiarity of this cycle compared with the other options is that the FTPA turbine is fed with gas after the OTPA turbine (consecutive turbine feeding scheme); in addition, a single by-pass before the turbine flow to control engine power is used.

This selected solution provides the best regulation capabilities to cover the design operational box, with lowest complexity; in addition, this scheme presents major commonalities with the demonstrator engine.

\section{CONCLUDING REMARKS}

1. In 2007-2014, under the terms of ASI-Roskosmos interagency agreement, KBKhA and AVIO with participation of ELV successfully conducted the complex of works on creation of the LOx-LNG expander cycle demonstrator engine. The works included: 
- design and manufacture of the demonstrator's components;

- autonomous "cold" and fire testing of the demonstrator's systems;

- manufacture of the demonstrator;

- preparation and checks of the stand systems; and

- fire tests of the demonstrator.

2. During the demonstrator's fire tests, the following tasks were achieved:

- the demonstrator's operability and correctness of the selected cyclogram;

- total operation time of $677 \mathrm{~s}$ at 11 ignitions;

- possibility of multiple ignitions during one startup day;

- stability of the combustion in the wide range of chamber pressure and mixture ratio operation processes; and

- possibility of startup in vacuum conditions.

3. During all the project phases, working together as an engine system responsible, AVIO-KBKhA joint propulsion team has demonstrated the spirit of fruitful collaboration and the chance to apply the best approaches from both Russian and European space industries.

4. The results obtained and the experience gained during the Demonstrator Engine activities create the reliable technical basis to start a development activities linked to the LM10-MIRA Flight Engine as the possible evolutions of the Vega launch vehicle, powering the VEGA-E 3rd stage. 